\title{
Geospatial tools for the identification of a malaria corridor in Estado Sucre, a Venezuelan north-eastern state
}

\author{
Laura Delgado-Petrocellii ${ }^{1}$, Alberto Camardiel ${ }^{2}$, Víctor Hugo Aguilar ${ }^{3}$, Néstor Martinez \\ Karenia Córdova ${ }^{3}$, Santiago Ramos ${ }^{1}$ \\ ${ }^{1}$ Ecological Information Systems and Environmental Modelling Laboratory (SIMEA), Institute of Tropical \\ Zoology, Central University of Caracas, Venezuela; ${ }^{2}$ Postgraduate Area in Statistics and Actuarial Sciences, \\ Faculty of Economy and Social Sciences, Central University of Caracas, Venezuela; ${ }^{3}$ Institute of Geography and \\ Regional Development, Faculty of Humanities and Education, Central University of Caracas, Venezuela; \\ ${ }^{4}$ School of Geography, Faculty of Humanities and Education, Central University of Caracas, Venezuela
}

\begin{abstract}
Landscape ecology research relies on frameworks based on geographical information systems (GIS), geostatistics and spatial-feature relationships. With regard to health, the approach consists of systems analysis using a set of powerful tools aimed at the reduction of community vulnerability through improved public policies. The north-oriental malaria focus, one of five such foci in Venezuela, situated in the north-eastern part of the Estado Sucre state, unites several social and environmental features and functions as an epidemiological corridor, i.e. an endemic zone characterised by permanent interaction between the mosquito vector and the human host allowing a continuous persistence of the malaria lifecycle. A GIS was developed based on official cartography with thematic overlays depicting malaria distribution, socio-economic conditions, basic environmental information and specific features associated with the natural wetlands present in the area. Generally, malaria foci are continuously active but when the malaria situation was modelled in the north-oriental focus, a differential, spatio-temporal distribution pattern situation was found, i.e. a situation oscillating between very active and dormant transmission. This pattern was displayed by spatial and statistical analysis based on the model generated in this study and the results were confirmed by municipal and county malaria records. Control of malaria, keeping the incidence at a permanently low level within the regional population, should be possible if these results are taken into account when designing and implementing epidemiological surveillance policies.
\end{abstract}

Keywords: malaria, geographical information system, remote sensing, spatial analysis, landscape ecology, epidemiological corridor, Venezuela.

\section{Introduction}

Climate pattern change, natural disasters, cumulative environmental impact and the emergence and reemergence of infectious diseases exert an increasing impact on the world of today. Examples of vulnerable communities with humans living under critical conditions due to poverty include localities ravished by malaria and/or other tropical diseases, and where the environment is negatively influenced by anthropogenic activity. In such places, a systemic approach is more than ever needed if we are to efficiently manage public health issues. The implementation of an effective environmental strategy based on the use of geospatial

Corresponding author:

Santiago Ramos

Ecological Information Systems and

Environmental Modeling Laboratory (SIMEA)

Caracas, Venezuela

Tel. +58 212605 1311; Fax +58 2126051204

E-mail: santiago.ramos@ciens.ucv.ve technologies such as digital terrain models (DTM), remote sensing, digital image processing and global positioning systems (GPS) is called for. These applications produce superior spatial analysis through integrated approaches based on geographical information systems (GIS) and open new possibilities to solve existing health problems. Advances in informatics and computational power, storage and handling of large volumes of data, have exploded during the latest decades and contributed to the development of new, powerful GIS approaches, capable of initiating novel ways and means to deal with diseases such as malaria, Chagas disease, dengue, leishmaniasis and other tropical diseases.

Early on, Kitron (1998) recognised the need for systemic approaches to study the epidemiology of parasitic diseases. In the People's Republic of China, the genetic discontinuity of the intermediate host snails of schistosomiasis was shown to be ultimately influenced by landscape ecology (Li et al., 2009), while Dongus et al. (2009) expose how agricultural and 
geographical features influence the presence of Anopheles larvae in urban areas in Dar es Salam, Tanzania. Some authors (Beck et al., 2000; Kitron, 2000) recommend spatial analysis and utilisation of the potential of GIS for infectious disease management, while others (Romaña et al., 2003) have conceptualised the epidemiological landscape notion in a way that underlines the importance of ecology. The idea of epidemic foci as part of landscape ecology is of paramount interest for our approach, as it holds that persistence of endemicity in a geographical locality is supported, indeed ensured, by environmental and edaphic (soil characteristic) conditions furthering the coexistence of parasite, vector and host (Romaña et al., 2003). Barrera et al., (1998) studied a malaria hotspot with strong transmission in Venezuela from that point of view, and this research group also applied this approach to characterise an epidemic of hemorrhagic dengue fever in this country (Barrera et al., 2000). Subsequently, Delgado and Ramos (2007) developed a systemic framework derived from the concept of landscape ecology by combining various technologies. This perspective not only provides a superior comprehension of the dynamics of rural malaria endemicity, but also highlights the relationship between spatial variables such as height and slope with malaria risk. The work presented here considers the malaria incidence in the Paria Peninsula, a region of the Estado Sucre state in Venezuela, in the light of geographical factors. Here, elementary landscape components such as the north-south variation between highland and lowland and the topographical coast-to-inland gradients are treated as a matrix displaying patches and corridor patterns with respect to this disease.

The hypothesis put forward holds that sequentially located malaria foci promote the establishment of conditions that support persistent disease, each focus generating/contributing to an epidemiological, endemic corridor by spatially relaying the disease along one or more geographical features. This important component of the ecological landscape concept provides a perspective that we have named "panoramic epidemiology" (Delgado et al., 2007), an approach capable of pinpointing environmental factors which could be decisive when designing effective policies for the control and surveillance of parasitic diseases. Our objective is to show, through the combination of spatial and statistical analyses, the presence and dynamics of an epidemiological malaria corridor in the Paria Peninsula part of Estado Sucre in the north-eastern part of Venezuela.

\section{Material and methods}

Study area

Paria Peninsula has a surface of $11,800 \mathrm{~km}^{2}$ and is located between latitudes $10^{\circ} 13^{\prime} 10^{\prime \prime}$ and $10^{\circ} 44^{\prime} 10^{\prime \prime}$ north and longitudes $61^{\circ} 50^{\prime} 44^{\prime \prime}$ and $64^{\circ} 30^{\prime} 00^{\prime \prime}$ "west (Fig. 1). The Estado Sucre state is divided into 15 municipalities, in turn subdivided into 55 smaller, administrative units called "parroquias".

\section{Spatial and epidemiological data}

The study was conducted using malaria incidence data gathered from records for the 28 parroquias that make up Paria Peninsula. The parroquia was taken as the spatial unit for the statistical analyses of the monthly records of the number of malaria cases reported to the local health centres between 1986 and 1999. These data were gathered from the malaria division of the former Ministry for Sanitation and Social Assistance (SAS) and the current state office in charge of regional public health (FUNDASALUD-SUCRE). The total number of cases included in the investigation was 4,704 .

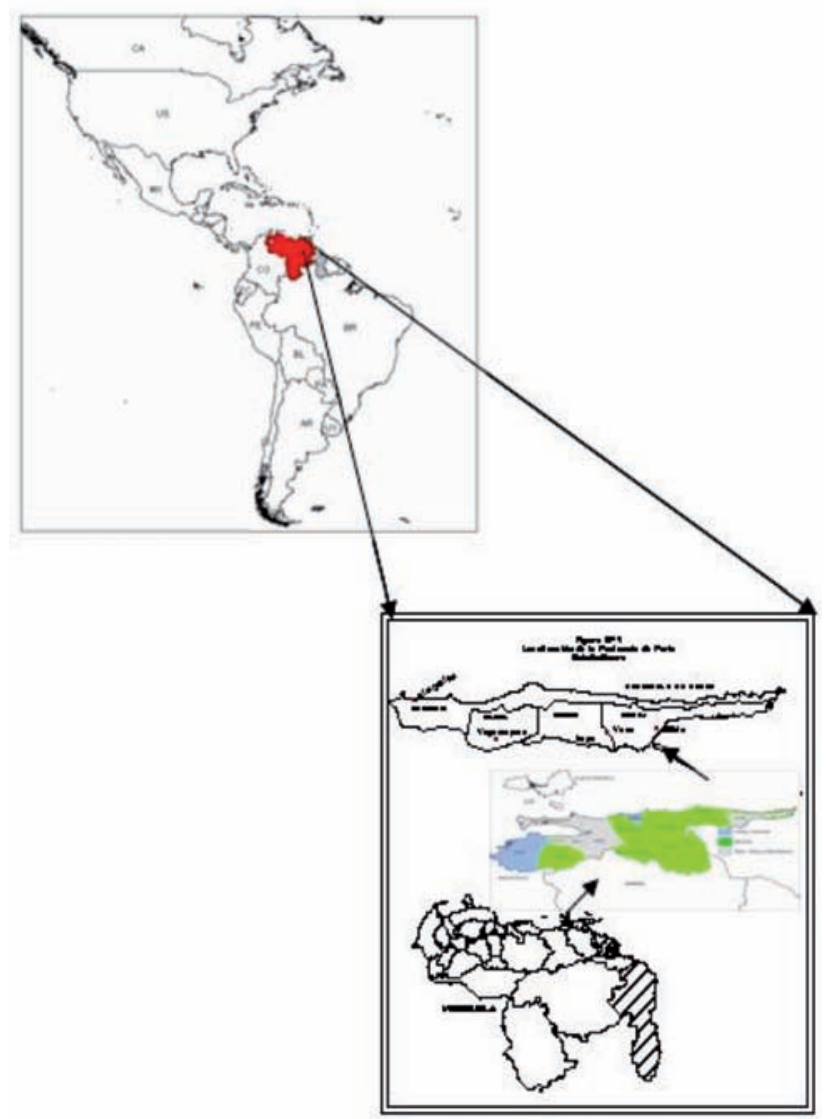

Fig. 1. Geographical location of the study area in Venezuela. 
The meteorological variables related to the El Niño Southern Oscillation (ENSO) phenomenon for each parroquia included in the study, were considered. Criteria from the National Oceanographic and Atmospheric Administration (NOAA) of the United States of America were used and the data corresponding to climatic variability came from registers published in reports by the NOAA Earth System Research Laboratory (ESRL; http://www.esrl. noaa.gov/). For the GIS approach we relied on basic vectorial covers (overlays) which include roads, main hydrographic information, human population centres as well as topographic information such as ground level curves plus height and slope. We included information on local climes including isohyets, i.e. lines drawn through geographical points recording equal amounts of precipitation during a specific period. GIS was also used to draw a response surface, whose line density was proportional to the number of cases per year and place. The spatial scale was 1:100,000.

\section{Methodology}

The full study period was 1986-1999, but we also generated some epidemiologic scenarios from 1997 to 1999 using the "Malaria Incidence Spatial Model" (MISM), previously developed by Delgado et al. (2001, 2007). We used ANOVA (http://www.anova .com/) for variance analysis to assess the overall significance of sets of main effects and interactions and side-by-side box-plots to display all the components of value-splitting by considering their mean squares. The usefulness of this approach to the study of the malaria incidence in the Paria Peninsula region was enhaced using a particularly robust and comprehensive version of ANOVA (Hoaglin et al., 1991). This approach

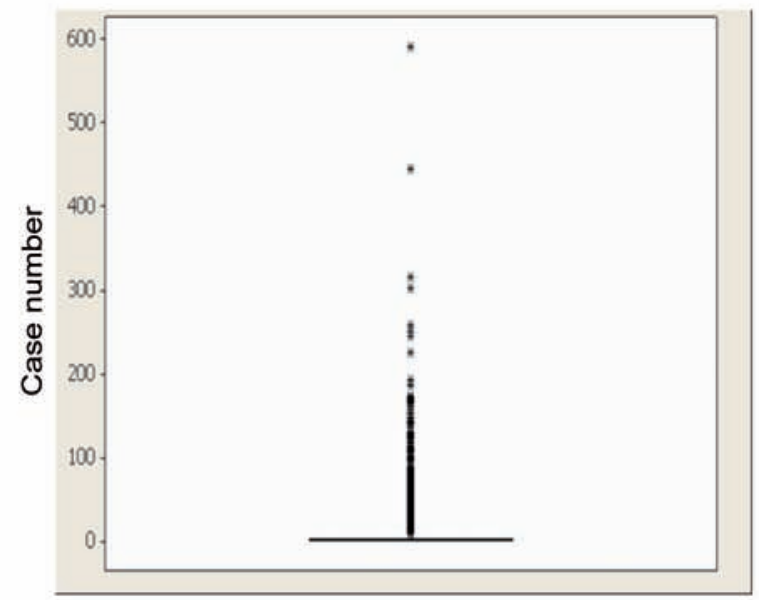

emphasises the exploratory point of view, while retaining the traditional methods of least-squares estimation. In addition to the ANOVA table, numerical and graphical displays were added to gain insight into the data structure. This technique facilitates the explanation of the effects of spatial and climatic variability produced by ENSO events taking intensity and frequency into account.

In order to confirm whether or not there is a statistically significant association between the number of malaria cases in the parroquias and the spatio-temporal factors under consideration, we analysed values, consisting of the natural logarithms +0.5 , of the number of malaria cases as a 4-way layout without replication. The transformation of the response was done in order to induce a more symmetric distribution of the transformed variable than the original one and to approximate the basic assumptions required to perform a valid ANOVA analysis (Figs. 2 and 3). Factors used to investigate the response variable included "Month" with 12 levels, the "Time Period" with two levels (1986-1989 and 1990-1999), the "ENSO Phenomenon" with seven levels (i.e. weak Niña, moderate Niña, strong Niña, neutral, weak Niño, moderate Niño, strong Niño) and the "Parroquia" unit with 28 levels.

Since the spatial factor presented a considerable effect on the number of malaria cases, we further analysed data using the multiple comparison test based on Tukey's honest significant difference (HSD) according to Hoaglin et al. (1991). All comparisons between the parroquias were done pair-wise controlling for the experimental error between the levels of the geographical factor. This procedure evaluates the difference between pairs of averages of the response variable assuring extra protection to control the over-

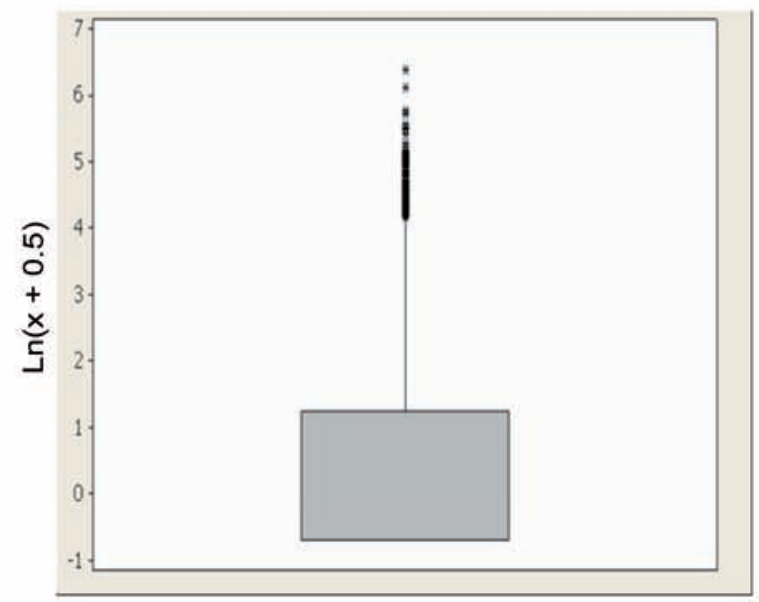

Fig. 2. Box-plots based on the number of malaria cases (left) and on the natural log of the case number +0.5 (right). 


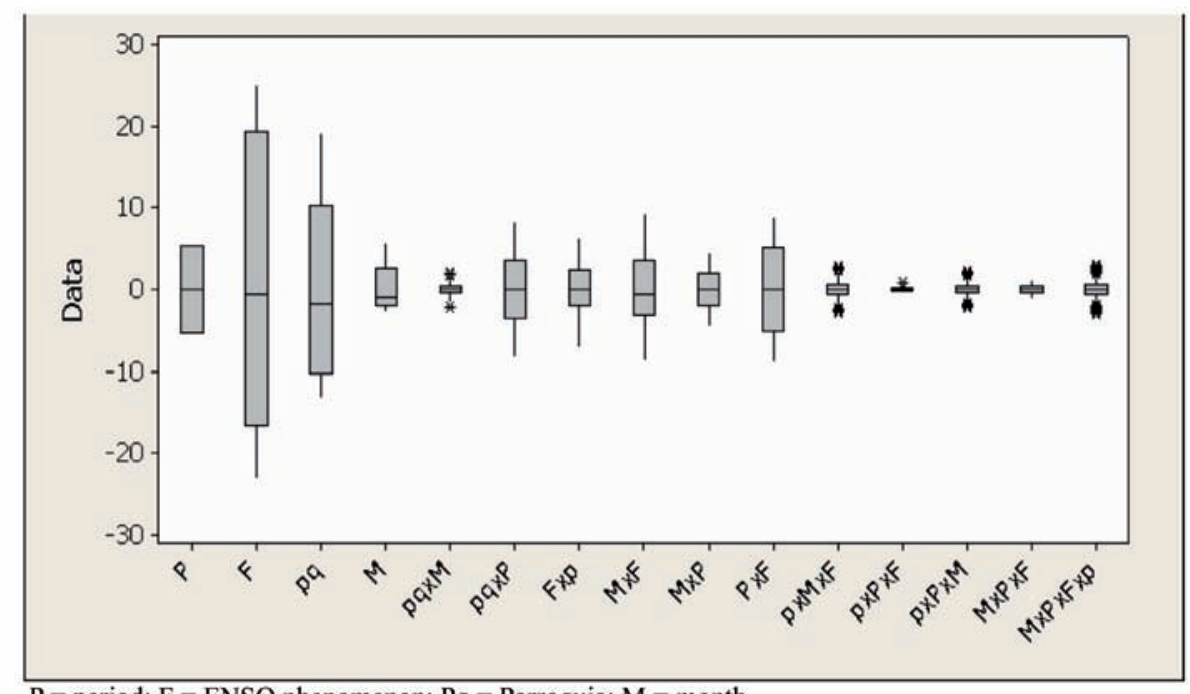

Fig. 3. Comparative box-plots of the adjusted factorial effects.

all error rate under the null hypothesis of no difference in the set of effects. The error rate is the probability that one or more comparisons lead to an incorrect conclusion of having found a significant difference.

\section{Results}

Table 1 gives the summary of the ANOVA results and Figure 3 displays side-by-side box-plots of the fitted main effects, double-factor interactions and residuals. The "Month" variable was found to have very small effect relative to the "Time Period", "ENSO
Phenomenon" and "Parroquia" ones, and was therefore deemed to be unimportant. Among the doublefactor interactions, "Period" + "ENSO" produced the largest effects. The largest values, positive or negative, issuing from the ANOVA analysis and the side-by-side box-plots (Fig. 3.), came from the "ENSO" and "Parroquia" variables, which also showed the largest main effects. Thus, there exists a strong statistically significant association $(\mathrm{P}<0.001)$ between the levels of the climatic factor, those of the spatial factor and those of the time factor (though this may be explained by the fact that the duration of each period was different).

Table 1. ANOVA results for the number of malaria cases (expressed as natural $\log +0.5$ ) of the effects of the variables and combinations thereof investigated.

\begin{tabular}{|c|c|c|c|c|c|}
\hline Source factors & DF & SS & MS & $\mathrm{F}$ ratio & $P$ value \\
\hline Month & 11 & 74.48 & 6.77 & 9.47 & $<0.001$ \\
\hline Period & 1 & 317.25 & 317.25 & 443.54 & $<0.001$ \\
\hline Parroquia & 27 & $3,364.58$ & 124.61 & 174.22 & $<0.001$ \\
\hline ENSO Phenomenon & 6 & $1,765.34$ & 294.22 & 411.35 & $<0.001$ \\
\hline Month * Period & 11 & 61.11 & 5.56 & 7.77 & $<0.001$ \\
\hline Month * Parroquia & 297 & 128.35 & 0.43 & 0.6 & 1.00 \\
\hline Month * ENSO & 66 & $1,102.86$ & 16.71 & 23.36 & $<0.001$ \\
\hline Period * Parroquia & 27 & 399.13 & 14.78 & 20.67 & $<0.001$ \\
\hline Period * ENSO & 6 & 181.37 & 30.23 & 42.26 & $<0.001$ \\
\hline Parroquia * ENSO & 162 & $1,161.24$ & 7.17 & 10.02 & $<0.001$ \\
\hline Month * Period * Parroquia & 297 & 146.46 & 0.49 & 0.69 & 1.00 \\
\hline Month * Period * ENSO & 66 & $1,205.56$ & 18.27 & 25.54 & $<0.001$ \\
\hline Month * Parroquia * ENSO & 1,782 & $1,307.84$ & 0.73 & 1.03 & 0.29 \\
\hline Period * Parroquia * ENSO & 1,62 & 242.73 & 1.50 & 2.09 & $<0.001$ \\
\hline Error & 1,782 & $1,274.61$ & 0.72 & & \\
\hline Total & 4,703 & $12,732.92$ & & & \\
\hline
\end{tabular}

DF, degrees of freedom; SS, sum of squares; MS, mean square. 
Furthermore, we found significant interactions between the climatic phenomenon and the temporal dimension, and between the temporal and the spatial dimensions, but they were much weaker than what was found for the main effects. The goodness of fit of the model given by the square multiple correlation coefficient $\left(\mathrm{R}^{2}\right)$ was $90 \%$ and the adjusted $\mathrm{R}^{2}$ for the number of factors in the model was $74 \%$.

The HSD-Tukey multiple comparison test confirmed the presence of a true, epidemiological corridor that is particularly evident due to the assisted effect of the road axis between the villages El Pilar and Guiria, situated within their homonymous parroquias (Table 2). We were able to define 11 homogeneous groups of parroquias that did not differ in terms of the response variable. The existence of a series of sets with different average numbers of malaria cases was verified. The sets could be ranked according to the average number

Table 2. The parroquias grouped according to the main effects gradient obtained by the HSD-Tukey procedure based on the number of malaria cases (expressed as natural $\log +0.5$ ).

\begin{tabular}{lll}
\hline Number & Parroquia & GRUPO 0 \\
\hline 18 & Puerto Santo & n. s. \\
21 & San Antonio de Irapa & n. s. \\
25 & Tunapuicito & n. s. \\
3 & Bideau & n. s. \\
11 & Francisco Antonio Vásquez & n. s. \\
6 & Cristóbal Colón & n. s. \\
12 & Guaraúnos & n. s. \\
4 & Campo Claro & n. s. \\
16 & Marabal & n. s. \\
10 & El Rincón & n. s. \\
23 & Soro & n. s. \\
7 & El Morro de Puerto Santo & n. s. \\
9 & El Pilar & n. s. \\
\hline
\end{tabular}

n. s., not significant of malaria cases starting with set no. 1 (G1), which had the highest average number of cases (Yaguaraparo, Irapa, El Paujil and El Pilar) down to set no. 10 (G10), which included the Guiria and Antonio José de Sucre parroquias. A zero set, consisting of 13 parroquias, had the lowest number of new malaria cases (Table 2).

With regard to slope, the gradient ranges between 0$2 \%$ and $2-5 \%$ showed the highest number of malaria cases. Figure 4 shows the malaria intensity during 1997, when foci appeared near the Campoma Lagoon in the Cariaco coastal zone as well as along the Paria Peninsula. A relationship was shown between localities situated in the lowlands (i.e. elevations not surpassing $100 \mathrm{~m}$ above the mean sea level). When the malaria dynamics were analysed and compared sequentially over the years it was possible, as described previously (Delgado et al., 2004; Delgado, 2005; Delgado and Ramos, 2007), to identify localities that correspond to particular malaria foci (Fig. 4). Interestingly, the same approach also worked when attempting to correlate malaria to height and slope with $200 \mathrm{~m}$ above the mean sea level appearing as the threshold variable in an ecological interpretation for the particular distribution of malaria in the region.

Figure 4 also shows that the northern coastal foci have diminished between 1997 and 1999, while those in the Paria zone persisted. When GIS overlays were produced, using contour lines simultaneously with the MISM (Delgado et al., 2001), clearer areas corresponding to higher localities appeared, most of them at the southern part of the state, in contrast to the darker areas that correspond to the lowlands particularly in the area of the Paria Peninsula. The risk for malaria transmission there is reinforced by nearby wetlands constitute ideal vector habitats promoting reproduction and maintenance of stable mosquito populations.
The malaria incidence in Paria Peninsula in 1997

A)

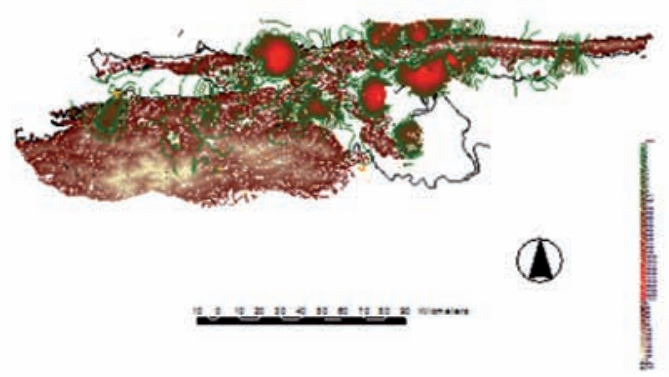

The malaria incidence in Paria Peninsula in 1999

B)

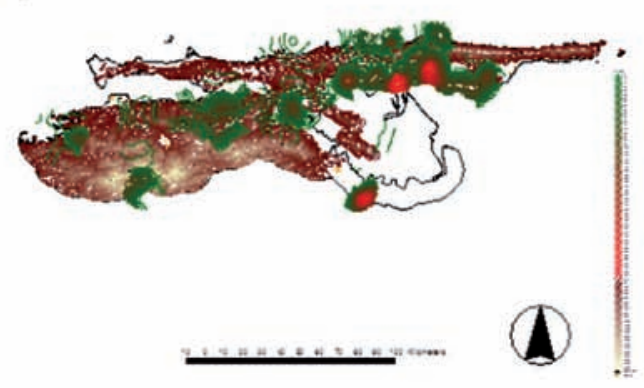

Fig. 4. The "Malaria Incidence Spatial Model" (MISM) for 1997 and 1999. 
The sequential map series (Fig. 5), generated by the spatial models, reveals an epidemiological corridor with permanently active foci. The existence of this epidemiologic corridor along this alignment is supported by the malaria records from the eleven sets of parroquias as seen in Table 2 and Figure 6.

\section{Discussion}

The MISM explains the malaria incidence and underlines the relevance of the spatially differential pattern of new cases of the disease, at least during the years 1997 and 1999. The application of this tech-

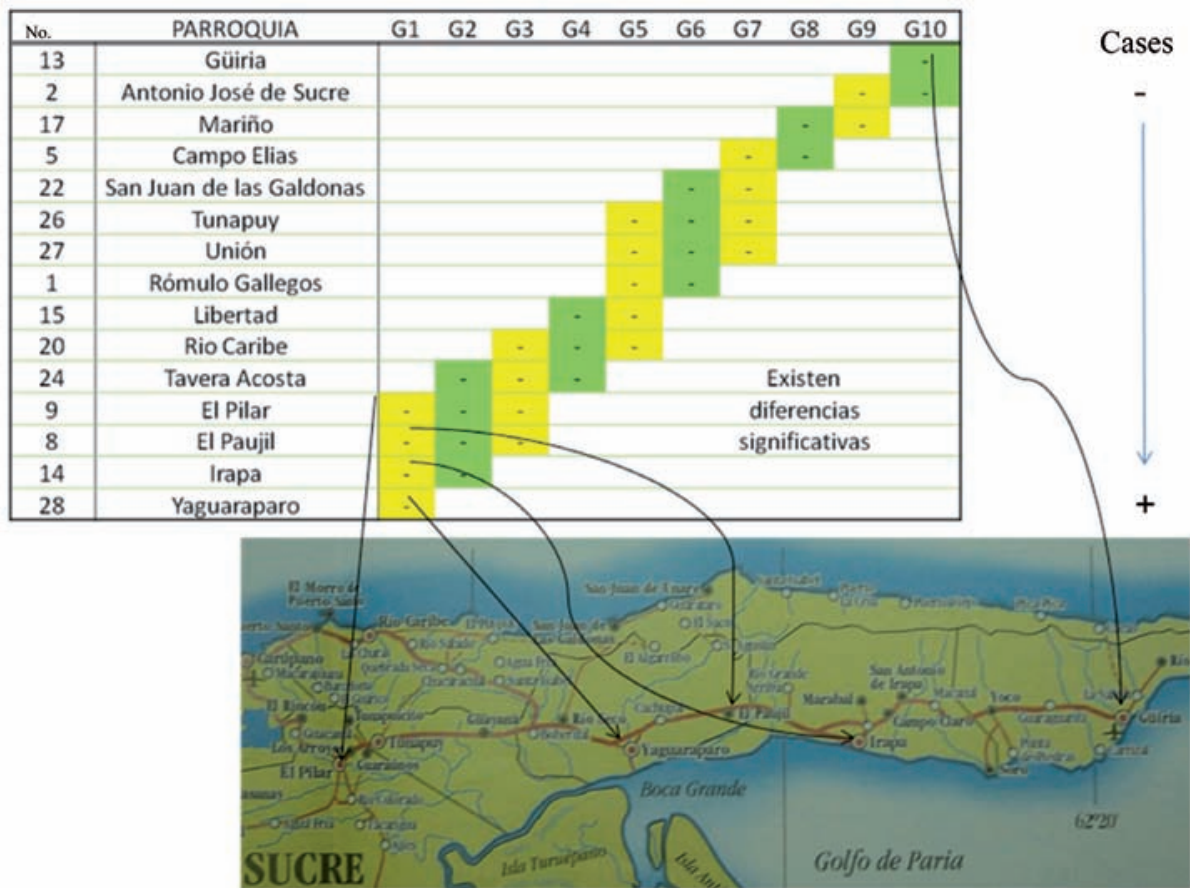

Fig. 5. An epidemiological corridor in Paria Peninsula, Estado Sucre, Venezuela.

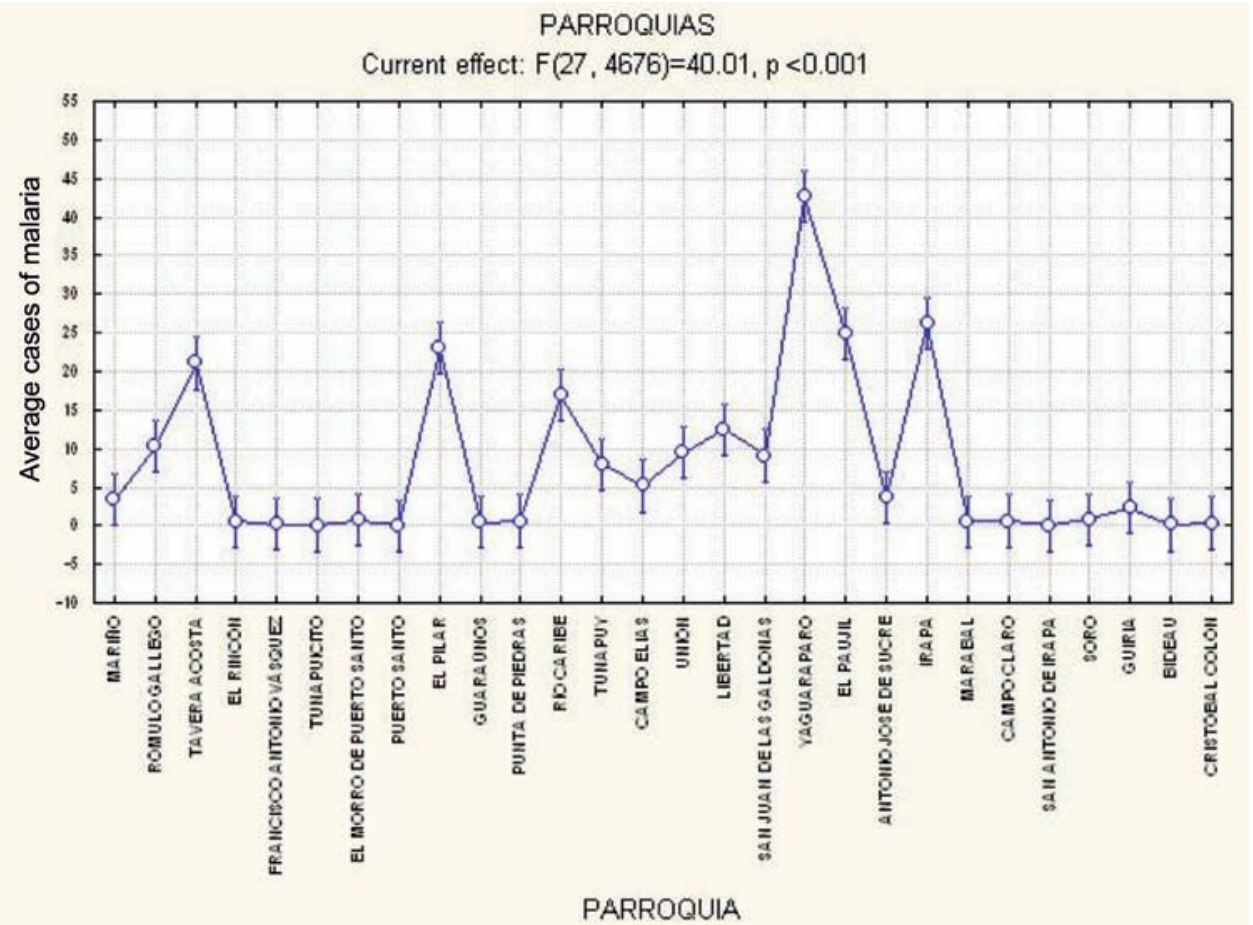

Fig. 6. Average number of malaria cases per Parroquia investigated. 
nique confirms the association of malaria incidence with foci located in lowlands with low-degree slopes as reported previously (Delgado, 2005). However, the lowlands were also chosen for the construction of the roads connecting the major human settlements in the region. These two facts not only define the major axis of population distribution between the localities of El Pilar, Yaguaraparo and Irapa, but also underline the predisposition of these human settlements to become active malaria foci. Thus, an epidemiological, endemic corridor with permanently active foci is established by a string of localities permanently connected by an active flow of people (Fig. 5).

The clear statistical association between climate and spatio-temporal effect, obtained from the ANOVA analysis, strengthens the validity of our results. There is a strong likelihood for the two levels of the "Period" variable to be significantly different because of their different lengths. The ecological interpretation of results points towards a relative spatial positioning of localities as responsible for differences of a distinct expression in terms of the number of malaria cases by locality. It also explains the persistence of transmission over time, although each locality suffered the same effect of climatic events along the annual cycle, i.e. all localities fell within the same pattern of weather fluctuation. The variable responses by locality suggest that the rates of malaria incidence are due to the geographical location within the landscape pattern structure. Thus, the characteristics of each locality are different with respect to the continuum of physic-environmental matrixes with variously adapted biotic components as suggested in the landscape ecosystem context. Thus, differences in the number of malaria cases (intensity), as well as persistence of infection in the human population, depend of a connectivity determined by the distance between settlements and areas suitable to maintain permanent vector populations.

The results of the analysis shown in Table 2 confirm the presence of an epidemiological corridor, a fact which is further strengthened by the existence of the road between El Pilar and Guiria, located within of their homonymous parroquias. The finding of 11 homogeneous groups of parroquias without differences in terms of the response variable within them, although clearly so between them, is particularly interesting because it shows the existence of sets of parroquias with stable differences with respect to the average number of malaria cases. The set with the highest average number (Yaguaraparo, Irapa, El Paujil and El Pilar) may act as the main focus for the rest of the corridor. It is evident from the spatial analysis that this set (G1) has a key location in the region as it unites areas with environmental conditions characteristic for the lowlands, including lowdegree slopes. Proximity to extensive wetlands which never completely dry out during the year plays an important role as it provides ample breeding places for the mosquito vector. This assures successful breeding and maintenance of permanent populations of Anopheles aquasalis, the main malaria vector of the zone, thus maintaining mosquito populations the year around with low variability. Since the lowland ecology is not only favourable for stable human habitation, it also represents a tract of land within the general landscape pattern that lends itself to diverse human outdoor activities. The overall effect is a high association between humans and mosquitoes confirming the existence of the epidemiologic corridor as an important element of this ecological landscape.

The combination of spatial and statistical analysis support the development of an effective approach to a serious public health problem, and the ecological interpretation allows the recognition of differences in response of each locality in terms of occurring malaria cases that does not depend on annual climatic fluctuations. The differences observed point towards the existence of different rates of infection in the human population in certain areas, explained by the spatial position of habitats in relation to areas with permanent mosquito populations. An intrinsic ecological relationship has been shown between the biotic component and the natural environmental landscape matrix, the responses of the biotic factors determining the seriousness of the malaria situation. This relation can be spatially expressed within an area by connectivity factors or spatial proximity factors, favouring both persistence and intensity of the disease. This configuration may appear in the form of a continuous, elongated pattern as in an epidemiological corridor, but when the area is small and relatively isolated, we talk about it as a hotspot response. Such configurations may be associated with ecological system features, first as a resilient, resistant area providing the backdrop for the establishment of an endemic zone. On the other hand, this presents malaria as an ecological subsystem nested inside a greater ecosystem with high sustainability. Then, both features may be considered in the design of surveillance and control policies, considering non-equal measures as strategies for action, especially with respect to early warning systems for susceptible areas. 


\section{Conclusions}

The settlement units (parroquias), based on territorial, socio-political divisions, can be ranked according to the average number of malaria cases in a way, which is consistent with the existence of a malaria epidemiological corridor in the Paria Peninsula. The existence of this endemic corridor, which can be understood as the outcome of particular, ecological characteristics present in the landscape, was confirmed by statistical analysis. Although effects caused by the change of global clime patters, conspicuous arrangements and functions of local ecosystems determine the expression of malaria in a region.

The design of surveillance and control measures should consider factors related to human mobility between settlements located in geographical areas of certain ecological characteristics and the spatial coincidence between human settlements and malaria vector mosquito's habitats.

\section{Acknowledgements}

The authors would like to express their gratitude for financial support in project CDCH 03-31-3981-2005 to Consejo de Desarrollo Científico y Humanístico $(\mathrm{CDCH})$, project UCV2001001850 to FONACIT, and project Hidroclimático G2005000184 to BID-FONACITII. Our thanks to all personnel from Zone 11, Malariología, Carúpano (Fundasalud-Sucre), and from the many sanitary dependencies for their support. Special thanks to Ing. Luis Díaz and Dr. Darío González.

\section{References}

Barrera R, Delgado N, Jiménez Villalobos, Romero I, 2000 Stratification of a city with hyperendemic dengue hemorrhagic fever. Rev Pan Sal Púb 8, 4.

Barrera R, Grillet ME, Rangel Y, Berti J, Aché A, 1998. Estudio eco-epidemiológico de la reintroducción de la malaria en el nororiente de Venezuela, mediante sistemas de información geográfica y sensores remotos. Boletín de la Dirección de Malariología y Saniamiento Ambiental 38, 14-30.

Beck LR, Lobitz BM, Wood BL, 2000. Remote sensing and human health: new sensors and new opportunities. Emerg
Infect Dis 6, 217-227.

Delgado L, 2005. La dinámica espacio-temporal del sistema malaria en el foco nor-oriental de Venezuela. Acta Biol Venez 25, 57-66.

Delgado L, Ramos S, 2007. The remote sensing perspective to focus landscape ecology, the anthropogenic action and the malaria disease. In: Space Technology for E-health. Space Technology-based Telehealth project initiatives in Latin America and the Caribbean. Edited by United Nations Programme on Space Applications, United Nations, New York, USA.

Delgado L, Ramos S, Camardiel A, 2007. La Malaria y su Contexto Espacial. El Caso Particular del Estado Sucre en Venezuela. XI Conferencia Iberoamericana de Sistemas de Información Geográfica (XI CONFIBSIG).

Delgado L, Ramos S, Martínez N, 2004. Antropogénesis y persistencia de malaria, estado Sucre-Venezuela. XI Simposio Latinoamericano en Percepción Remota y Sistemas de Información Espacial (SELPER), Chile.

Delgado L, Ramos S, Rodríguez R, Liberal L, 2001. Modelo espacial de riesgo malárico para el estado Sucre, Venezuela. Rev Ing Fac Ing UCV 16, 15-26.

Dongus S, Nyika D, Kannady K, Mtasiwa D, Mshinda H, Gosoniu L, Drescher AW, Fillinger U, Tanner M, Killeen GF, Castro MC, 2009. Urban agriculture and Anopheles habitats in Dar es Salaam, Tanzania. Geospat Health 3, 189-210.

Hoaglin D, Mosteller F, Tukey J, 1991. Exploratory Analysis of Variance, John Wiley and Sons (eds), New York, USA.

Kitron U, 1998. Landscape ecology and epidemiology of vectorborne diseases: tools for spatial analysis. J Med Entomol 35, 435-445.

Kitron U, 2000. Risk maps: transmission and burden of vectorborne diseases. Parasitol Today 16, 324-325.

Li SZ, Wang YX, Yang K, Liu Q, Wang Q, Zhang Y, Wu XH, Guo JG, Bergquist R, Zhou XN, 2009. Landscape genetics: the correlation of spatial and genetic distances of Oncomelania hupensis, the snail intermediate host of Schistosoma japonicum in mainland China. Geospat Health 3, 221-231.

Romaña C, Emperaire L, Janssen AM, 2003. Enfoques conceptuales y propuestas metodológicas para el estudio de las interacciones entre el medio ambiente y la salud: aplicación de un programa de investigación sobre la tripanosomiasis americana. Cad Saú Púb 19, 945-953. 